\title{
Evaluation of infectious complications after haploidentical hematopoietic stem cell transplantation with post-transplant cyclophosphamide following reduced-intensity and myeloablative conditioning: a study on behalf of the Francophone Society of Stem Cell Transplantation and Cellular Therapy (SFGM-TC)
}

\begin{abstract}
Amandine Fayard ${ }^{1} \cdot$ Elisabeth Daguenet $\mathbb{1}^{1} \cdot$ Didier Blaise $^{2} \cdot$ Patrice Chevallier $^{3} \cdot$ Hélène Labussière $^{4}$. Ana Berceanu ${ }^{5}$ - Ibrahim Yakoub-Agha ${ }^{6}$ - Gérard Socié $\mathbb{B D}^{7}$ - Amandine Charbonnier ${ }^{8}$ - Felipe Suarez ${ }^{9}$. Anne Huynh $^{10} \cdot$ Mélanie Mercier $^{11} \cdot$ Claude-Eric Bulabois $^{12} \cdot$ Bruno Lioure $^{13} \cdot$ Sylvain Chantepie ${ }^{14} \cdot$ Yves Beguin $^{15}$. Jean-Henri Bourhis ${ }^{16} \cdot$ Jean-Valère Malfuson $^{17} \cdot$ Laurence Clément $^{18} \cdot$ Régis Peffault de la Tour $^{7} \cdot$ Jérôme Cornillon $^{1}$
\end{abstract}

Received: 29 October 2018 / Revised: 25 January 2019 / Accepted: 3 February 2019 / Published online: 15 February 2019 (c) Springer Nature Limited 2019

\begin{abstract}
Several approaches have been developed to overcome historical barriers associated with poor outcomes in the setting of HLA-haploidentical allogeneic transplantation (HaploSCT). Here, we examine the outcome of patients with various hematological disorders undergoing HaploSCT with high-dose, post-transplantation cyclophosphamide. We performed a retrospective study on 381 patients from 30 centers between January 2013 and December 2015. At the last follow-up, a total of 1058 infectious episodes were diagnosed, affecting $90.3 \%$ of the cohort. Median time to first infection was 13 days for bacterial, 32 days for viral and 20 days for fungal infections. Around $41 \%$ of these infections were of bacterial origin and $35 \%$ of viral origin, among which $48.8 \%$ of patients presented CMV reactivation. Median of GVHD relapse-free survival, progression-free survival and overall survival were 7.1 months, 19.9 months and 33.5 months, respectively. HSCT procedure was the primary or contributing cause of death (55.6\%), followed by relapse of the original disease (34.2\%). Infections accounted for $45.7 \%$ of the HSCT-related deaths. The present multicenter data on a large cohort of patients receiving HaploSCT with PTCy confirmed the feasibility of the procedure with an acceptable incidence of infectious complications, not different as compared to other haploidentical platforms or HLA-matched transplantation.
\end{abstract}

Supplementary information The online version of this article (https:// doi.org/10.1038/s41409-019-0475-7) contains supplementary material, which is available to authorized users.

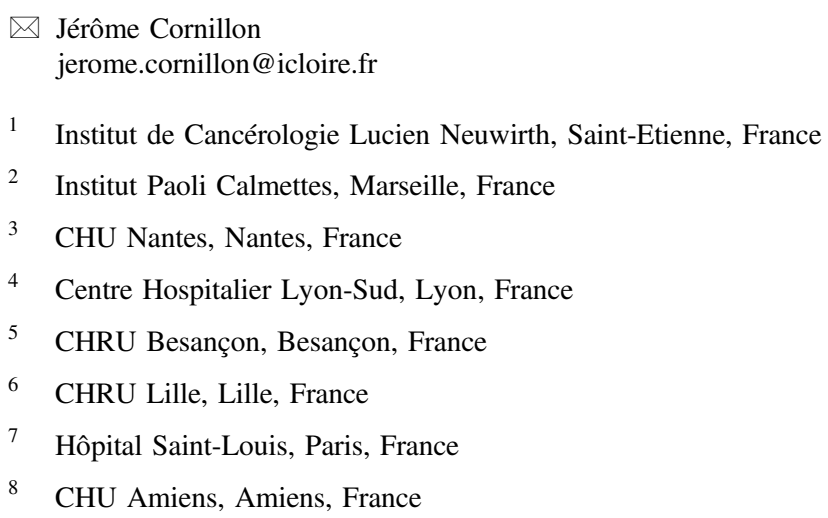

\section{Introduction}

Pioneer attempts of haploidentical stem cell transplantation (HaploSCT) following myeloablative conditioning and

\footnotetext{
9 Hôpital Necker, Paris, France

10 Institut Universitaire du Cancer, Toulouse, France

11 CHU Angers, Angers, France

12 CHU Grenoble, Grenoble, France

13 CHU Hautepierre, Strasbourg, France

14 Institut d'Hématologie Caen, Caen, France

15 CHU Sart Tilman, Liège, Belgium

16 Centre Gustave Roussy, Villejuif, France

17 Hôpital d'instruction des armées Percy, Paris, France

18 Hôpital Universitaire, Bordeaux, France
} 
combined with a standard graft-vs.-host disease (GVHD) prophylaxis were characterized by an intense bidirectional alloreactivity which in turn induced a high incidence of graft failure, GVHD development and treatment-related mortality [1]. To overcome these alloresponses, ex vivo T-cell depletion permitted to reduce GVHD incidence but opportunistic infections were increased due to high level of immunodepression [2]. To date, numerous studies including a variety of hematological malignancies have evaluated the safety and effectiveness of post-transplantation cyclophosphamide (PTCy) in unmanipulated grafts, and reported considerable benefits of this therapeutic scheme in terms of low incidence of non-relapse mortality (NRM) and low incidence of severe acute and chronic GVHD [3-7]. Despite tremendous progresses in optimizing treatment modalities, the in-depth immunosuppression therapy creates a permissive territory for pathogens. Viral reactivations such as cytomegalovirus (CMV) or Epstein-Barr virus (EBV), bacteremia, fungal and parasitic infections are classically described after allogeneic stem cell transplantation (alloSCT) [8]. Currently, data on infectious complications are still limited and are mostly documented as secondary end points during HaploSCT [2, 4, 7, 9-11]. In this study, we retrospectively and particularly assessed the incidence of infectious complications after HaploSCT with PTCy without ex vivo T-cell depletion in a large cohort of 381 patients.

\section{Patients and methods}

This study was approved by the SFGM-TC board and conducted in agreement with the declaration of Helsinki. Informed consent was obtained from all subjects. Clinical data were obtained through ProMISe (Project Manager Internet Server), from 29 French centers and one Belgian center.

\section{Study design, inclusion criteria and data collection}

This was a registry-based retrospective multicenter study including patients 18 years or above who underwent HaploSCT between January 2013 and December 2015. Patients younger than 18 years at transplantation and those with nonhematological malignancies were excluded. Referring local physicians were asked to confirm the diagnosis, clinical history, treatment lines, disease status at the time of HaploSCT, data on the HaploSCT, outcomes including GVHD grading and infectious complications, and an updated follow-up.

\section{Conditioning, transplant modalities and prophylaxis}

Peripheral blood stem cells (PBSC) $(73 \%)$ or bone marrow (BM) (27\%) were used as stem cell source for transplantation with no ex vivo T-cell depletion. Patients received either a myeloablative (MAC) or a reduced-intensity conditioning (RIC) regimen according to their age and comorbidity, center's practices and disease stage. Most patients were treated with a RIC $(81 \%)$ with a majority of Baltimore scheme [4]. GVHD prophylaxis consisted of high-dose cyclophosphamide $(50 \mathrm{mg} / \mathrm{kg})$ administered on days +3 and +4 after Haplo, in combination with an anticalcineurin and mycophenolate mofetil starting on day +5 . No thymoglobulin was used in this cohort. The median total nucleated cell count was $7 \times 10^{8} / \mathrm{kg}(4-10)$, and the median CD34+ cell count was $5 \times 10^{6} / \mathrm{kg}(3-7)$. Diagnosis strategies for individual pathogens, particularly viral and fungal infections, varied between centers based on local laboratory practices. Infection prophylaxis was performed according to institutional standard practice or were based on recommendations [12]. In short, all patients received large antimicrobial prophylaxis combining antifungal, antibiotic, antiviral and antiparasitic agents: a $\beta$-lactam-based prophylaxis for pneumococci and encapsulated bacteria starting after aplasia, acyclovir or valacyclovir to prevent herpes and varicella infections, cotrimoxazole or atovaquone for Pneumocystis infections, fluconazole for fungal infections or posaconazole in case of GVHD.

\section{Definitions}

Neutrophil engraftment was defined as achieving absolute neutrophil count (ANC) $\geq 0.5 \times 10^{9} / \mathrm{L}$ for 3 consecutive days, and platelet engraftment was defined as achieving platelet count $\geq 20 \times 10^{9} / \mathrm{L}$ unsupported by platelet transfusions for 7 days. Acute GVHD (aGVHD) and chronic GVHD (cGVHD) were defined per published criteria $[13,14]$.

Infection data were collected retrospectively by each investigator, from conditioning until the patient's death or last follow-up. Infectious complications were defined by a systemic inflammatory response syndrome associated with a microbiologically (blood culture collection, collection of culture sample from any site with suspect infection) or/and clinically and/or radiologically documentation (chest X-ray, scanner, magnetic resonance imaging and so on). A fever not explained by a non-infectious cause was also analyzed. Infectious complications were specified as follows. (i) A severe bacterial infection was defined as bacteremia by any bacterial organism, in a febrile patient. Bacterial infections were divided into early (occurring within the first 30 days post-transplant) and late infections (occurring beyond day 30). (ii) CMV infection was defined as the presence of a single pp65 antigen-positive leukocyte or a positive viremia in peripheral blood, as well as documentation of CMV disease without prior positive antigenemia or viremia. CMV disease was defined as the demonstration of CMV in biopsy or autopsy specimens from clinically involved visceral sites 
Table 1 Characteristics of patients in the study group $(N=381)$

\begin{tabular}{|c|c|}
\hline Characteristics & Value \\
\hline Median age of patients, years (range) & $51.9(35.5-60.7)$ \\
\hline \multicolumn{2}{|l|}{ Gender of patients } \\
\hline Male & $238(62.5)$ \\
\hline Female & $143(37.5)$ \\
\hline \multicolumn{2}{|l|}{ Diagnosis } \\
\hline Acute leukemia/myelodysplatic syndrome & $208(54.6)$ \\
\hline Hodgkin or non-Hodgkin's lymphoma & $115(30.2)$ \\
\hline Myeloproliferative disease & $31(8.1)$ \\
\hline Multiple myeloma or solitary plasmacytoma & $15(3.9)$ \\
\hline Chronic leukemia & $10(2.6)$ \\
\hline Bone marrow failure syndrome & $2(0.5)$ \\
\hline $\begin{array}{l}\text { Median interval from diagnosis to transplantation, months } \\
\text { (range) }\end{array}$ & $19.5(7.7-38.5)$ \\
\hline Previous transplant & $143(37.6)$ \\
\hline Autologous & 78 \\
\hline Allogeneic & 65 \\
\hline \multicolumn{2}{|l|}{ Disease status at transplantation } \\
\hline CR or VGPR & $204(53.5)$ \\
\hline PR & $44(11.5)$ \\
\hline Relapse & $44(11.5)$ \\
\hline PD & $47(12.3)$ \\
\hline SD & $18(4.7)$ \\
\hline Other & $24(6.3)$ \\
\hline \multicolumn{2}{|l|}{ CMV serostatus } \\
\hline $\mathrm{D}-/ \mathrm{R}+$ & $3(21.7)$ \\
\hline $\mathrm{D}+/ \mathrm{R}-$ & $36(9.5)$ \\
\hline $\mathrm{D}+/ \mathrm{R}+$ & $131(34.3)$ \\
\hline $\mathrm{D}-/ \mathrm{R}-$ & $122(32.0)$ \\
\hline Unknown pair & $9(2.7)$ \\
\hline \multicolumn{2}{|l|}{ Type of conditioning regimen } \\
\hline RIC & $307(80.6)$ \\
\hline MAC & $73(19.2)$ \\
\hline \multicolumn{2}{|l|}{ Stem cell source } \\
\hline PBSC & $278(73)$ \\
\hline $\mathrm{BM}$ & $103(27)$ \\
\hline \multicolumn{2}{|l|}{ Graft composition } \\
\hline $\mathrm{CD} 34+$ cells, $10^{6} / \mathrm{kg}$ (range) & $5.1(3.4-7.3)$ \\
\hline $\mathrm{CD} 3+$ cells, $10^{7} / \mathrm{kg}$ (range) & $19.5(5.21-29.7)$ \\
\hline
\end{tabular}

Values are total number of cases with percent in parentheses, unless otherwise noted

$B M$ bone marrow, $C R$ complete remission, $D$ donor, $P B S C$ peripheral blood stem cell, $M A C$ myeloablative conditioning, $P D$ progressive disease, $C M V$ cytomegalovirus, $P R$ partial remission, $R$ recipient, $R I C$ reduced-intensity conditioning, $S D$ stable disease, $V G P R$ very good partial response

by culture and/or histology, or if CMV was detected in culture (conventional or shell-vial) of bronchoalveolar lavage samples in the presence of new or changing pulmonary infiltrates. (iii) BK virus, human herpesvirus-6 (HHV-6) or EBV infection viremia testing were based on a quantitative PCR method of viral DNA copies $/ \mathrm{mL}$. (iv) Invasive fungal infections were divided in invasive aspergillosis, candidemia and other mycoses. Invasive aspergillosis gathered possible event (clinical signs and symptoms plus a compatible thoracic computed tomography scan or $\mathrm{X}$-ray), probable event (clinical signs and symptoms, compatible X-ray findings plus a positive respiratory tract culture for Aspergillus spp.) and definite event (positive histology for an invasive mold infection by aspergillus). (v) Pneumonia of unknown origin was defined as any new radiological lung infiltrate in a febrile patient with respiratory symptoms in the absence of a known pathogen or another evident diagnosis. This set of definitions was used by all participating centers, according to the Infectious Disease Working Party of the European Group for Blood and Marrow Transplantation.

\section{Statistical analysis}

Median values and ranges were used for continuous variables and percentages as well as frequency for categorical variables. Survival times were measured from the date of the graft infusion to the date of event or the date of last contact (censored data). Grade II-IV aGVHD and cGVHD, infections as well as CMV reactivation were calculated using the cumulative incidence (CI) methods Engraftment and relapse were estimated using proportions. Relapse and death from any cause were considered events. Statistical analyses were performed with $\mathrm{R}$ software (3.2.5) and $\mathrm{R}$ packages survival.

\section{Results}

\section{Patients, disease and transplant characteristics}

Patients and disease characteristics are summarized in Table 1. A total of 381 patients were included between January 2013 and December 2015. Patients were transplanted for acute myeloid or lymphoid leukemia or myelodysplastic syndrome $(n=208)$, myeloproliferative disease $(n=31)$, Hodgkin or non-Hodgkin's lymphoma $(n=115)$, multiple myeloma $(n=15)$, chronic leukemia $(n=10)$ and bone marrow failure syndrome $(n=2)$. Thirty-seven percent of patients had received at least a previous HSCT (68 autologous and 65 allogeneic). The median age at transplantation was 55.7 years (38.7-62.8). Most of the patients (65\%) underwent HaploSCT in partial or complete remission. The type of conditioning varied according to the disease. Donor CMV seronegativity $\left(\mathrm{D}-\mathrm{CMV}^{-}\right) /$recipient CMV seronegativity $\left(\mathrm{R}_{-} \mathrm{CMV}^{-}\right)$was recorded in 122 cases $(32.0 \%)$, and in 250 cases $(65.6 \%), \mathrm{D}_{-} \mathrm{CMV}^{+}$and/or R$\mathrm{CMV}^{+}$was present. Complete data on CMV serostatus were unavailable for 9 cases $(2.4 \%)$.

\section{Overall outcomes}

Median follow-up of the cohort was 8.5 months (Q1-Q3, 3.7-19.3; range, 0.07 to 52.5). Median follow-up of 
Table 2 Engraftment, chimerism, HaploSCT-related toxicities and outcomes $(N=381)$

\begin{tabular}{lc}
\hline Characteristics & Value \\
\hline Time to engraftment (days, (range) $)$ & \\
ANC $>0.5 \times 10^{9} / \mathrm{L}(N=354)$ & $25(17-23)$ \\
PLT $>20 \times 10^{9} / \mathrm{L}(N=263)$ & \\
Chimerism day +100 & $288(75.6)$ \\
Full & $34(8.9)$ \\
Partial & $9(2.4)$ \\
Patient reconstitution & $3(0.8)$ \\
Aplasia & $47(12.4)$ \\
Unknown & $113(29.7)$ \\
aGVHD & $107(94.7)$ \\
Grade II-IV & $34(30.1)$ \\
Grade III-IV & $6(5.3)$ \\
Unknown & $73(19.2)$ \\
cGVHD & $37(50.7)$ \\
Limited & $30(41.1)$ \\
Extensive & \\
Disease status & $258(67.8)$ \\
CR or VGPR & $47(12.4)$ \\
PR & $20(5.2)$ \\
Relapse & $8(2.1)$ \\
PD & $2(0.5)$ \\
SD & $46(12.1)$ \\
Other & \\
\hline Values are & \\
&
\end{tabular}

Values are total number of cases with percent in parentheses, unless otherwise noted

HaploSCT haploidentical stem cell transplantation, aGVHD acute GVHD, $A N C$ absolute neutrophil count, $C R$ complete remission, $G V H D$ graft-vs.-host disease, $P L T$ platelet, $P D$ progressive disease, $P R$ partial remission, $S D$ stable disease, $V G P R$ very good partial response

surviving patients was 16.5 months (range, 5.3-24.9) and median follow-up of patients who survived without relapse, graft failure or new malignancy was 17.1 months (range, 5.3-25.5). While a total of 350 patients (92\%) achieved an absolute neutrophil count of $0.5 \times 10^{9} / \mathrm{L}$ in a median of 20 days (17-23), 296 patients (77.7\%) achieved an untransfused platelet count of $20 \times 10^{9} / \mathrm{L}$ in a median time of 25 days (18-32). At day 35, 360 patients were evaluable and 4 graft failures were observed (1\%). CI of acute grade II-IV and grade III-IV GVHD was $31.4 \%$ and $11.5 \%$ at day +100 , respectively; cGVHD was $48.2 \%$ at 50 months. The median overall survival (OS) was 33.5 months and the median progression-free survival (PFS) was 19.9 months. The median GVHD-free and relapse-free survival (GRFS) was 7.1 months $(95 \% \mathrm{CI}, 6.1-10.8)$. Transplant-related mortality was of $11 \%(95 \% \mathrm{CI}, 7.7-14.1)$ and $24 \%(95 \%$ CI, 19.3-28.8) at day +100 and day +365 post transplantation, respectively. During the follow-up period, 149 patients $(39.1 \%)$ died, of which 82 patients $(55.0 \%)$ were relapse-free. The most common cause of deaths was related to the HSCT procedure (55.6\%), followed by relapse or progression of the original disease $(34.2 \%)$. For $10.2 \%$ of patients, causes of death remained unknown. Infections ( $n$ $=37$ ) were the primary or contributing cause of transplantation-related deaths: $45.9 \%(n=17)$ were of bacterial origin, $18.9 \%(n=7)$ multiple infectious origins, $16.2 \%(n=6)$ viral, $10.8 \%(n=4)$ fungal and $8.1 \%(n=3)$ parasitic. CI of infection-associated treatment-related mortality was $22.4 \%$ at 1 year post transplantation. CI of relapse was $38.2 \%$ at the end of the study. Data from engraftment, chimerism and HaploSCT-related toxicities and outcomes are summarized in Table 2.

\section{Infectious complications}

At the last follow-up, a total of 1058 infectious episodes were diagnosed using microbiological and/or clinical criteria (Table 3). About $15 \%$ of the cases were not microbiologically documented, but clinically documented, and only $3 \%$ of fever episodes were reported without clinical manifestations and/or microbiological documentation. Three hundred and forty-four patients $(90.3 \%)$ experienced at least one infection, with a median of 2 events/patients (14) and a median onset to first infection of 13 days (6-27). Two hundred and thirty-two patients $(67 \%)$ presented a complication after day +20 . Around $45 \%$ of the patients experienced more than 2 infections, with 60 patients having more than 5 episodes. Median time to first infection was 13 days for bacterial, 32 days for viral and 20 days for fungal infections. CI of first infectious complications, including clinical infections, was $90.6 \%$ at 12 months, $57.4 \%$ for bacterial and $61.4 \%$ for viral infections. CI of first and documented infections was $83 \%$ at 12 months (Fig. 1a). Among the 1058 reported episodes, the most common sites were bloodstream $(54 \%)$, respiratory tract $(15 \%)$, urinary tract $(10 \%)$, digestive tract $(7 \%)$ and skin (4\%). Among the 113 patients with aGVHD grade II-IV, 41 patients (36\%) experienced infectious complications, whereas 56 patients (21\%) with no signs of GVHD developed infections after day +30 . Incidence of infection per 1000 patient-days was subdivided by standard periods of infectious risk. Bacterial infections mostly occurred before day +30 , whereas viremia (viral infection or reactivation) was predominant between day +30 and day +100 (Fig. 1b). Among the 1022 infectious episodes with details on the timing, 55 events $(5.38 \%)$ manifested after 1 year post transplantation.

\section{Bacterial infections}

As a first complication, 157 patients (45.6\%) experienced a bacterial infection, with a total of 438 bacterial infections 
Table 3 Infectious complications $(N=381)$

\begin{tabular}{|c|c|}
\hline Characteristics & Value \\
\hline \multicolumn{2}{|l|}{ Patients with infectious complications } \\
\hline Yes & $344(90.3)$ \\
\hline No & $37(9.7)$ \\
\hline Total number of infections & 1058 \\
\hline $\begin{array}{l}\text { Median number of infectious complications/patient ( } n \\
\text { (range)) }\end{array}$ & $2(1-4)$ \\
\hline \multicolumn{2}{|l|}{ Number of infectious complications/patient } \\
\hline 1 to 2 & $172(45.1)$ \\
\hline 3 to 5 & $112(29.4)$ \\
\hline$>5$ & $60(15.7)$ \\
\hline Bacterial infections & $438(41.3)$ \\
\hline \multicolumn{2}{|l|}{ Gram-negative bacilli (59.3\%) } \\
\hline Enterobacteriaceae species & $66.5 \%$ \\
\hline Pseudomonadaceae species & $20.0 \%$ \\
\hline Xanthomonadaceae species & $1.5 \%$ \\
\hline Legionellaceae species & $1.5 \%$ \\
\hline \multicolumn{2}{|l|}{ Gram-positive cocci $(32.2 \%)$} \\
\hline Staphylococcus species & $66 \%$ \\
\hline Enterococcus species & $23.4 \%$ \\
\hline Streptococcus species & $9.9 \%$ \\
\hline \multicolumn{2}{|l|}{ Gram-positive bacilli (8.2\%) } \\
\hline Clostridium species & $86.1 \%$ \\
\hline Viral infections & $375(35.4)$ \\
\hline $\mathrm{CMV}$ & $39.7 \%$ \\
\hline $\mathrm{BKV}$ & $18.1 \%$ \\
\hline HHV-6 & $17.3 \%$ \\
\hline EBV & $8.0 \%$ \\
\hline VZV & $2.9 \%$ \\
\hline Fungal infections & $78(7.3)$ \\
\hline Aspergillus species & $43.6 \%$ \\
\hline Candida species & $33.3 \%$ \\
\hline Pneumocystis species & $12.8 \%$ \\
\hline Parasitic infections $^{\mathrm{a}}$ & $8(0.8)$ \\
\hline Nondocumented & $159(15)$ \\
\hline
\end{tabular}

Values are total number of cases with percent in parentheses, unless otherwise noted

$B K V$ BK virus, $C M V$ cytomegalovirus, $H H V-6$ human herpesvirus-6, $E B V$ Epstein-Barr virus, $V Z V$ varicella-zoster virus

${ }^{\mathrm{a}}$ For Toxoplasma gondii

(41.3\% of total infections) during the follow-up period. Gram-negative bacilli were the most prevalent microorganisms (59.3\%) with a majority of Enterobacteriaceae. Staphylococcus species were responsible for $66 \%$ of infections by Gram-positive cocci $(32.2 \%$ of bacterial infections), with a predominance of coagulase-negative staphylococci $(61.7 \%)$. In addition, 33 cases of infections related to Enterococcus species and 14 related to Streptococcus species were also reported. A total of 36 Gram- positive bacilli infections were identified, 31 were related to Clostridium difficile. After day +30 , majority of bacterial infections (66\%) are due to Gram-negative bacteria.

\section{Viral infections}

A total of 375 viral infections (35.4\% of total infections) were reported. CMV reactivation was noticed in 122 patients $(48.8 \%)$. Median time of CMV reactivation was 39 days (27-52). The CI of CMV reactivation by day +200 was $61.2 \%$ in $\mathrm{D}_{-} \mathrm{CMV}^{-} / \mathrm{R}_{-} \mathrm{CMV}^{+}, 54.7 \%$ in $\mathrm{D}-\mathrm{CMV}^{+} / \mathrm{R}-$ $\mathrm{CMV}^{+}$and $31.2 \%$ in $\mathrm{D}_{-} \mathrm{CMV}^{+} / \mathrm{R}_{-} \mathrm{CMV}^{-}$. Seventeen patients $(4.5 \%)$ experienced $\mathrm{CMV}$-associated disease, affecting the gut in 6 cases and 11 pneumonias. BK virus (BKV)-related hemorrhagic cystitis (HC) accounted for $18.1 \%$ of viral infections. Median onset of BK virus was 41 days (range, 29-41). We also reported 65 episodes of HHV-6 reactivations, and 30 for EBV, 11 infections related to varicella-zoster virus (VZV), 9 related to respiratory syncytial virus and herpes simplex virus, 8 related to parvovirus and 6 related to adenovirus. Further detail is provided for other viruses in Supplementary Table 1.

\section{Fungal and parasitic infections}

Fungal infections were diagnosed in 78 patients with a median occurrence of 20 days from HaploSCT (13-60). Invasive aspergillosis was the most common infection (43.6\%), followed by invasive candidiasis (33.3\%) and pneumocytosis (12.8\%). Additionally, 8 parasitic infections with Toxoplasma gondii were reported. A detailed overview of these infective epidodes is provided in Supplementary Table 1.

\section{Discussion}

The present analysis describes the amount of infectious complications on hematological patients transplanted with unmanipulated haplo receiving PTCy as GVHD prophylaxis. So far, our study has included the largest cohort of over 350 patients with a multicenter experience, thereby providing additional information on detailed infectious complications to previously published reports. To date, literature data with a special focus on infectious complications are not thorough and usually they are limited to small cohorts and monocentric experiences [2, 7, 9-11, 15]. HaploSCT has emerged as an option for patients who lacked suitable human leukocyte antigen (HLA)-matched donor, but complications are the most common causes of morbidity and mortality. It is also known that the extent of mismatch disparity correlates with the rate of infections, in the allogeneic HSCT setting [16, 17]. More importantly, we 

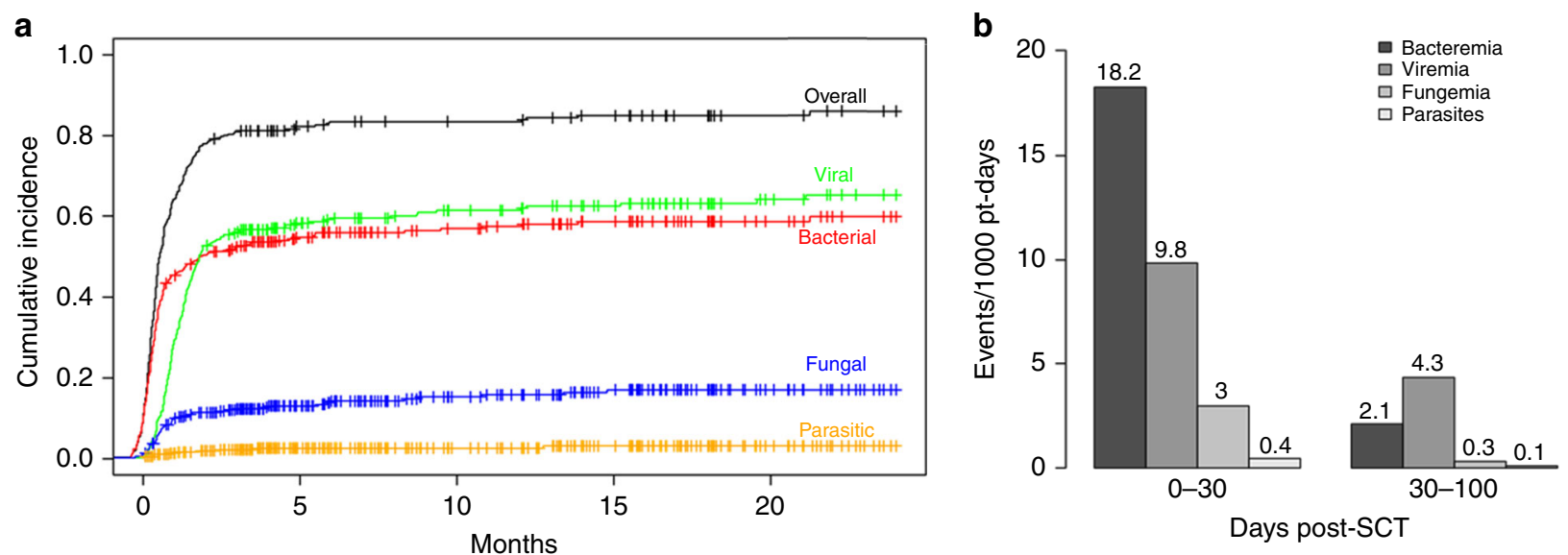

Fig. 1 First Infectious complications following haploidentical transplantation with post-transplantation cyclophosphamide. a Cumulative incidence of documented infections by pathogen type. b First infection rates at different post-transplant intervals by pathogen type

Table 4 Review of the literature: infectious complications in the HaploSCT with PTCy setting

\begin{tabular}{|c|c|c|c|}
\hline Reference & $N$ & $\begin{array}{l}\text { Transplant } \\
\text { charac. }\end{array}$ & Infectious complications \\
\hline Luznik et al. [4] & 68 & $\begin{array}{l}\text { Graft, BM } \\
\text { Cond, MAC }\end{array}$ & $26 \%$ CMV reactivation, $7 \%$ IFI \\
\hline Ciurea et al. [2] & 32 & $\begin{array}{l}\text { Graft, BM } 97 \% \\
\text { Cond, MAC } 81 \%\end{array}$ & $\begin{array}{l}35 \% \text { Bacterial infections, } 55 \% \text { viral infections, } 47 \% \text { CMV } \\
\text { reactivation, } 34.4 \% \text { BK, 9\% IFI }\end{array}$ \\
\hline Raiola et al. [7] & 50 & $\begin{array}{l}\text { Graft, BM } \\
\text { Cond, MAC }\end{array}$ & $\begin{array}{l}50 \% \text { CMV reactivation, } 4 \% \text { CMV-associated disease, } 40 \% \\
\mathrm{HC}, 26 \% \mathrm{BK}, 18 \% \text { IFI }\end{array}$ \\
\hline $\begin{array}{l}\text { Castagna et al. } \\
{[11]}\end{array}$ & 69 & $\begin{array}{l}\text { Graft, BM } 67 \% \\
\text { Cond, MAC }\end{array}$ & $41 \%$ Bacterial infections, $41 \% \mathrm{CMV}$ reactivation, $7 \% \mathrm{HC}$ \\
\hline $\begin{array}{l}\text { Crocchiolo et al. } \\
\text { [9] }\end{array}$ & 70 & $\begin{array}{l}\text { Graft, BM } 94 \% \\
\text { Cond, NMA } \\
68 \%\end{array}$ & $\begin{array}{l}40 \% \text { Bacterial infections, } 55 \% \text { viral infections, } 50 \% \text { CMV } \\
\text { reactivation, } 4 \% \text { CMV-associated disease, } 19 \% \text { HC, } 14 \% \\
\text { BK, } 5 \% \text { IFI }\end{array}$ \\
\hline Slade et al. [10] & 104 & $\begin{array}{l}\text { Graft, PBSC } \\
\text { Cond, NMA } \\
59 \%\end{array}$ & $\begin{array}{l}46 \% \text { Bacterial infections, } 52 \% \text { viral infections, } 55 \% \mathrm{CMV} \\
\text { reactivation, } 15 \% \mathrm{CMV} \text {-associated disease, } 19 \% \mathrm{HC}, 32 \% \\
\mathrm{BK}, 2.2 \% \text { IFI }\end{array}$ \\
\hline Fayard et al. & 381 & $\begin{array}{l}\text { Graft, PBSC } \\
73 \% \\
\text { Cond, RIC } 81 \%\end{array}$ & $\begin{array}{l}\text { 40.9\% Bacterial infections, } 34.1 \% \text { viral infections, } 34.1 \% \\
\text { CMV reactivation, } 4.5 \% \text { CMV-associated disease, } 18 \% \mathrm{HC} \text {, } \\
18 \% \text { BK, } 6.1 \% \text { IFI }\end{array}$ \\
\hline
\end{tabular}

These studies documented the rate of various infectious complications, with either a general interest on global infectious complications or a special focus on some specific pathogens

$B K \mathrm{BK}$ virus, $\mathrm{BM}$ bone marrow, charac. characteristics, Cond conditioning, $C M V$ cytomegalovirus, HaploSCT haploidentical stem cell transplantation, HC hemorrhagic cystitis, IFI invasive fungal infection, MAC myeloablative conditioning, NMA non-myeloablative, PBSC peripheral blood stem cell, PTCy posttransplantation cyclophosphamide, RIC reduced-intensity conditioning found that $90 \%$ of the patients experienced at least one infection and these complications were a primary or contributing cause of death for less than half of the patients who died in the follow-up period. Not surprisingly, bacteria were the leading responsible pathogens during the preengraftment phase, whereas viral infections were predominant in the early post-engraftment period. Our results are in line with previous reports in the setting of HaploSCT or HLA-matched transplants $[2,4,7,9-11,18-20]$
(Table 4). An inherent aspect of retrospective studies is the lack of exhaustiveness of collected data, especially during the follow-up period. This might largely explain the low rate of infectious diseases after day 100 as these events were not systematically reported.

Neutrophil recovery is an important factor determining the risk of bacterial infections after allo-HSCT. Indeed, approximately $30 \%$ of the patients have a bacterial infection, most frequently Gram-negative bacteria and coagulase-negative 
staphylococci [21]. We found a rate of $40.9 \%$ of bacterial infections as well as $57.4 \% \mathrm{CI}$ at 12 months, with a peak in the day 0 to day 30 period at a rate of approximately 18.2 per 1000 patient-days. Of note, the rate of bacterial infections found here was comparable to the $40-46 \%$ reported in analogous haploidentical settings. Slade et al. [10] described a similar overall rate of bacterial infections and reported a slightly lower incidence within the first 30 days of about 14 events per 1000 patient-days. In the cohort of 70 patients from Crocchiolo et al. [9], the rate of bacterial infections was about $40 \%$ with approximately 11 per 1000 patients-days during this specific period. The higher incidence of early bacterial infections that we found here may be explained by differences in routine bacterial prophylaxis that has been administered according to center's practices.

Regarding viral infections, we observed a remarkable lower rate of viral infections (34.1\%) as compared to previous publications that reported rates of about $52-55 \%$ [2, $9,10]$. Yet, the overall rate was in accordance with those related to allo-HSCT that account for 20 to $30 \%$ of all infections [18]. Consistent with the fact that viral infection was more prominent in the early post-engraftment period [10], we also noticed that virus accounted for around 50\% of infectious complications after day +20 . In addition, in our series, the CI of viral infections at 12 months (61.4\%) was lower than in previous literature (vs. $77 \%$ in Crocchiolo et al. [9] and about $80 \%$ in Slade et al. [10]). This incidence is probably underestimated considering the high incidence of cGVHD and it might be explained by a non-extensive reporting after day +100 .

Among the viral infections, CMV reactivation and human polyomavirus BK cystitis were the most frequent. The $34.1 \%$ of CMV reactivations, with $4.5 \%$ of CMVassociated diseases, coincided with the $21-34 \%$ reported in alloSCT settings $[18,22]$. In the context of HaploSCT, one can depict variable incidences of CMV reactivations, varying from $26 \%$ [4] up to $55 \%$ [2, 9-11]. One possible explanation is the absence of documented threshold that defines viral load requiring treatment initiation, given that this aspect might differ according to centers. The heterogeneity in the donor/recipient CMV serological status due to geographical and ethnological characteristics has also to be taken into account. We also noticed that $18 \%$ of patients developed BKV-associated HC. In our cohort, only symptomatic BK reactivations are described. This complication usually occurs in 20-60\% of HSCT recipients according to the different studies [23-27]. The low incidence of HC in this population was noteworthy compared to other studies $[2,7]$ and higher incidence in the literature is due to BK reactivation without symptoms. It has been previously shown that the conditioning regimen is an important factor for the development of $\mathrm{HC}[25,26]$. Moreover, it has also been proven that cyclophosphamide use and alternative donors favor the occurrence of HC [27]. It cannot be ignored that the vast majority of these patients received a RIC regimen, suggesting that the incidence of $\mathrm{HC}$ is probably biased by this parameter. Therefore, further prospective monitoring of BK viruria together with evaluations of immune reconstitution after transplantation is likely to deeply discern this complication.

Fungal infections remain an important cause of morbidity and mortality among patients undergoing allo-HSCT, with an incidence ranging from 6 to $10 \%$, and are associated with high mortality rates $(33 \%)[28,29]$. Invasive aspergillosis has a high prevalence $(80 \%$ from total invasive fungal infections), whereas invasive candidiasis (11\%), zygomycosis (4\%) and fusariosis (2\%) are less observed [8]. Despite a prolonged immunosuppression with PTCy, we observed an incidence of fungal infections of about $6 \%$, among which half were related to Aspergillus species. These results were into the range of previous reports $[4,9,10]$.

Several groups have conducted retrospective studies to compare outcomes from haploidentical transplants with PTCy to other transplants platforms, including HLA-matched, mismatched unrelated donors and umbilical cord blood as the donor source $[30,31]$. Overall, these reports showed equivalent outcomes between allo-HSCT and alternative donor transplantation approaches. As to NRM, it appears to vary depending on the studies, ranging from 8 to $30 \%$, in the context of HaploSCT [32]. It is noticeable that NRM associated to infections is estimated up to $20 \%$ [31]. Thus, we can describe similar NRM and infection-related NRM, even if heterogeneity for these parameters is still questionable as a consequence of the inclusion of patients with diverse disease stages and because of variable rates of cGVHD.

Our cohort is currently the largest cohort that described infectious complications after HaploSCT with PTCy. Yet, our retrospective study is somehow limited, especially regarding the availability of accurate documentation and the absence of detailed immune reconstitution. Moreover, most patients received RIC regimen which might be less prone to infection risks. In this context, it would be necessary to conduct a prospective study comparing the incidence of infectious complications after HaploSCT vs. related or unrelated allo-HSCT, in patients who received a similar conditioning regimen. The lack of data exhaustiveness, about the immune reconstitution profile, as well as the heterogeneity of the viral infections with various significance thresholds, are also weak points. Therefore, further studies with standardized conditions would be required to better document these variables.

\section{Compliance with ethical standards}

Conflict of interest The authors declare that they have no conflict of interest. 
Publisher's note: Springer Nature remains neutral with regard to jurisdictional claims in published maps and institutional affiliations.

\section{References}

1. Beatty PG, Clift RA, Mickelson EM, Nisperos BB, Flournoy N, Martin PJ, et al. Marrow transplantation from related donors other than HLA-identical siblings. N Engl J Med. 1985; 313:765-71.

2. Ciurea SO, Mulanovich V, Saliba RM, Bayraktar UD, Jiang Y, Bassett $\mathrm{R}$, et al. Improved early outcomes using a $\mathrm{T}$ cell replete graft compared with $\mathrm{T}$ cell depleted haploidentical hematopoietic stem cell transplantation. Biol Blood Marrow Transplant. 2012;18:1835-44.

3. O'Donnell PV, Luznik L, Jones RJ, Vogelsang GB, Leffell MS, Phelps M, et al. Nonmyeloablative bone marrow transplantation from partially HLA-mismatched related donors using posttransplantation cyclophosphamide. Biol Blood Marrow Transplant. 2002;8:377-86.

4. Luznik L, O'Donnell PV, Symons HJ, Chen AR, Leffell MS, Zahurak M, et al. HLA-haploidentical bone marrow transplantation for hematologic malignancies using nonmyeloablative conditioning and high-dose, posttransplantation cyclophosphamide. Biol Blood Marrow Transplant. 2008;14:641-50.

5. Cho B-S, Yoon J-H, Shin S-H, Yahng S-A, Lee S-E, Eom K-S, et al. Comparison of allogeneic stem cell transplantation from familial-mismatched/haploidentical donors and from unrelated donors in adults with high-risk acute myelogenous leukemia. Biol Blood Marrow Transplant. 2012;18:1552-63.

6. Solomon SR, Sizemore CA, Sanacore M, Zhang X, Brown S, Holland HK, et al. Haploidentical transplantation using $\mathrm{T}$ cell replete peripheral blood stem cells and myeloablative conditioning in patients with high-risk hematologic malignancies who lack conventional donors is well tolerated and produces excellent relapse-free survival: results of a prospective phase II trial. Biol Blood Marrow Transplant. 2012;18:1859-66.

7. Raiola AM, Dominietto A, Ghiso A, Di Grazia C, Lamparelli T, Gualandi F, et al. Unmanipulated haploidentical bone marrow transplantation and posttransplantation cyclophosphamide for hematologic malignancies after myeloablative conditioning. Biol Blood Marrow Transplant. 2013;19:117-22.

8. Sahin U, Toprak SK, Atilla PA, Atilla E, Demirer T. An overview of infectious complications after allogeneic hematopoietic stem cell transplantation. J Infect Chemother. 2016; 22:505-14.

9. Crocchiolo R, Bramanti S, Vai A, Sarina B, Mineri R, Casari E, et al. Infections after T-replete haploidentical transplantation and high-dose cyclophosphamide as graft-versus-host disease prophylaxis. Transpl Infect Dis. 2015;17:242-9.

10. Slade M, Goldsmith S, Romee R, DiPersio JF, Dubberke ER, Westervelt $\mathrm{P}$ et al. Epidemiology of infections following haploidentical peripheral blood hematopoietic cell transplantation. Transpl Infect Dis. 2017;19:1-10.

11. Castagna L, Crocchiolo R, Furst S, Bramanti S, El Cheikh J, Sarina B, et al. Bone marrow compared with peripheral blood stem cells for haploidentical transplantation with a nonmyeloablative conditioning regimen and post-transplantation cyclophosphamide. Biol Blood Marrow Transplant. 2014;20:724-9.

12. Brissot E, Alsuliman T, Gruson B, Hermet E, Tirefort Y, YakoubAgha I, et al. [How to manage EBV reactivation and EBV-PTLD, CMV and human herpesvirus 6 reactivation and infection after allogeneic stem cell transplantation: A report of the SFGM-TC (update)]. Bull Cancer. 2017;104:S181-S187.
13. Przepiorka D, Weisdorf D, Martin P, Klingemann HG, Beatty P, Hows J, et al. 1994 Consensus Conference on Acute GVHD Grading. Bone Marrow Transplant. 1995;15:825-8.

14. Arora M, Klein JP, Weisdorf DJ, Hassebroek A, Flowers MED, Cutler CS, et al. Chronic GVHD risk score: a Center for International Blood and Marrow Transplant Research analysis. Blood. 2011;117:6714-20.

15. Aversa F, Prezioso L, Manfra I, Galaverna F, Spolzino A, Monti A. Immunity to Infections after Haploidentical Hematopoietic Stem Cell Transplantation. Mediterr J Hematol Infect Dis. 2016;8: e2016057.

16. Fabricius WA, Ramanathan M. Review on haploidentical hematopoietic cell transplantation in patients with hematologic malignancies. Adv Hematol. 2016;2016:5726132.

17. Atilla E, Atilla PA, Bozdağ SC, Demirer T. A review of infectious complications after haploidentical hematopoietic stem cell transplantations. Infection. 2017;45:403-11.

18. Young J-AH, Logan BR, Wu J, Wingard JR, Weisdorf DJ, Mudrick $\mathrm{C}$, et al. Infections after transplantation of bone marrow or peripheral blood stem cells from unrelated donors. Biol Blood Marrow Transplant. 2016;22:359-70.

19. Mikulska M, Del Bono V, Bruzzi P, Raiola AM, Gualandi F, Van Lint MT, et al. Mortality after bloodstream infections in allogeneic haematopoietic stem cell transplant (HSCT) recipients. Infection. 2012;40:271-8.

20. Wingard JR, Hsu J, Hiemenz JW. Hematopoietic stem cell transplantation: an overview of infection risks and epidemiology. Infect Dis Clin North Am. 2010;24:257-72.

21. Mikulska M, Del Bono V, Viscoli C. Bacterial infections in hematopoietic stem cell transplantation recipients. Curr Opin Hematol. 2014;21:451-8.

22. Valadkhani B, Kargar M, Ashouri A, Hadjibabaie M, Gholami K, Ghavamzadeh A. The risk factors for cytomegalovirus reactivation following stem cell transplantation. J Res Pharm Pract. 2016;5:63-9.

23. Arthur RR, Shah KV, Charache P, Saral R. BK and JC virus infections in recipients of bone marrow transplants. J Infect Dis. 1988;158:563-9.

24. Lunde LE, Dasaraju S, Cao Q, Cohn CS, Reding M, Bejanyan N, et al. Hemorrhagic cystitis after allogeneic hematopoietic cell transplantation: risk factors, graft source and survival. Bone Marrow Transplant. 2015;50:1432-7.

25. Gilis L, Morisset S, Billaud G, Ducastelle-Leprêtre S, LabussièreWallet H, Nicolini F-E, et al. High burden of BK virus-associated hemorrhagic cystitis in patients undergoing allogeneic hematopoietic stem cell transplantation. Bone Marrow Transplant. 2014;49:664-70

26. Silva Lde P, Patah PA, Saliba RM, Szewczyk NA, Gilman L, Neumann J. et al. Hemorrhagic cystitis after allogeneic hematopoietic stem cell transplants is the complex result of BK virus infection, preparative regimen intensity and donor type. Haematologica. 2010;95:1183-90.

27. Ruggeri A, Roth-Guepin G, Battipaglia G, Mamez A-C, Malard F, Gomez A, et al. Incidence and risk factors for hemorrhagic cystitis in unmanipulated haploidentical transplant recipients. Transpl Infect Dis. 2015;17:822-30.

28. Girmenia C, Raiola AM, Piciocchi A, Algarotti A, Stanzani M, Cudillo L, et al. Incidence and outcome of invasive fungal diseases after allogeneic stem cell transplantation: a prospective study of the Gruppo Italiano Trapianto Midollo Osseo (GITMO). Biol Blood Marrow Transplant. 2014;20:872-80.

29. Kontoyiannis DP, Marr KA, Park BJ, Alexander BD, Anaissie EJ, Walsh TJ, et al. Prospective surveillance for invasive fungal infections in hematopoietic stem cell transplant recipients, 20016: overview of the Transplant-Associated Infection Surveillance 
Network (TRANSNET) Database. Clin Infect Dis. 2010; 50:1091-1100.

30. Robinson TM, O’Donnell PV, Fuchs EJ, Luznik L. Haploidentical bone marrow and stem cell transplantation: experience with post-transplantation cyclophosphamide. Semin Hematol. 2016; 53:90-7.
31. Kanakry CG, Fuchs EJ, Luznik L. Modern approaches to HLAhaploidentical blood or marrow transplantation. Nat Rev Clin Oncol. 2016;13:10-24.

32. Montoro J, Sanz J, Sanz GF, Sanz MA. Advances in haploidentical stem cell transplantation for hematologic malignancies. Leuk Lymphoma. 2016;57:1766-75. 